\title{
Inhibition of Galectins with Small Molecules
}

\author{
Christopher T. Öberga ${ }^{a}$ Hakon Leffler ${ }^{b}$, and Ulf J. Nilsson ${ }^{* a}$
}

\begin{abstract}
Evidence that the galectin family of proteins plays crucial roles in cancer, inflammation, and immunity has accumulated over the last decade. The galectins have consequently emerged as interesting drug targets. A majority of galectin functions occurs by means of cross-linking glycoproteins and by doing so controlling glycoprotein cellular localization and residence times. The glycoprotein cross-linking occurs when galectin dimers or multimers, or galectins with two binding sites, bind galactose-containing glycans of the glycoproteins. Such galectin-glycan interactions have been successfully blocked with compounds having multivalent presentation of galactose, lactose, or $\mathrm{N}$-acetyllactosamine, with peptides, and with small carbohydrate (galactose) derivatives. This review summarizes and analyzes attempts to develop efficient and selective small-molecule galectin inhibitors through derivatization of monosaccharides, mainly galactosides, with non-carbohydrate structures that protrude into subsites adjacent to the core-conserved galactose-recognizing site of the galectins.
\end{abstract}

Keywords: Cancer $\cdot$ Galectin · Immunity · Inflammation · Inhibitor

\section{The Galectins - An Introduction}

The galectin family of $\beta$-galactosidebinding proteins has been ascribed importance in a wide range of biological mechanisms. ${ }^{[1]}$ For example, intracellular trafficking, ${ }^{[2]}$ cell signaling ${ }^{[3-6]}$ apoptosis, ${ }^{[7]}$ and cell adhesion ${ }^{[8]}$ are regulated by galectin activities. These galectin activities are observed as effects on the organism level in inflammation, immunity, and cancer progression. ${ }^{[9-13]}$ Deciphering galectin mechanistic pathways on a molecular level has accelerated during the last decade. A characteristic galectin feature, which is commonly connected to their biological activities, is that they simultaneously present multiple carbohydrate recognition domains (CRD) which allows galectins to cross-link their glycoprotein ligands. This is achieved in three principal ways governed by galectin structural features. The so-called prototype galectins that have one CRD within their polypeptide chain form non-covalent dimers. The tandem-repeat

\footnotetext{
${ }^{*}$ Correspondence: Prof. Dr. U. J. Nilsson ${ }^{a}$

Tel.: +46 462228218

Fax: +46 462228209

E-mail: ulf.nilsson@organic.lu.se

aOrganic Chemistry, Lund University

POB 124, SE-221 00 Lund, Sweden

bection MIG, Department of Laboratory Medicine

Lund University

Sölvegatan 23, SE-223 62 Lund, Sweden
}

galectins have two CRD within their polypeptide chain. The only chimera-type galectin, galectin-3, carries a proline-rich collagen-like $\mathrm{N}$-terminal linked to a C-terminal CRD. The galectin-3 collagen-like $\mathrm{N}$-terminal is responsible for galectin-3 multimerization and hence glycoprotein cross-linking properties.

Recent investigations have advanced the understanding of key galectin functions, such as the discoveries that different cell surface protein glycosylation patterns on different regulatory T-cells control galectin-1-binding and subsequent T-cell apoptosis, ${ }^{[3]}$ that galectin- 8 orchestrates intracellular targeting, ${ }^{[14,15]}$ and that galectin3-induced lattice formation with branched $\mathrm{N}$-glycans regulates cell surface receptor localization. ${ }^{4-6]}$ Furthermore, raft-independent apical sorting of proteins is regulated via galectin-3-controlled intracellular glycan-dependent clustering.[2,16,17] More recently, it was demonstrated that CD8-TCR co-localization was abolished by galectin-TCR lattice formation, which conferred anergy in tumor-infiltrating CD8+ lymphocytes.[18]

All these observations have led to the hypothesis that galectins are potential targets for novel anti-cancer and anti-inflammatory compounds. Support for such a hypothesis has been demonstrated in several in vivo studies with an amino acid-derived lactulose-amine ${ }^{[19,20]}$ and a modified citrus pectin (MCP). ${ }^{[21,22]}$ both proposed to inhibit galectin-3, as well as with galectininhibitory lactosyl steroids ${ }^{[23]}$ and with peptides (Anginex) ${ }^{[24,25]}$ proposed to inhibit angiogenesis by blocking galectin-1. Some of the more recent in vivo studies point towards a mechanism where the inhibitors enhance the efficiency of other chemotherapeutica presumably by blocking a galectin-mediated anti-apoptotic ${ }^{[20]}$ or pro-migratory effect. ${ }^{[23]}$ Hence, discovery of novel selective and potent galectin inhibitors remains an important task. ${ }^{[26,27]}$

\section{Inhibition Strategies}

A number of strategies for inhibiting the function of the galectins have been reported.[27] Natural smaller saccharide fragments, such as galactose, lactose and $\mathrm{N}$-acetyllactosamine, can be and have been used in numerous experiments. However, small fragments of natural oligosaccharides suffer from the drawback of typically low affinity (high $\mu \mathrm{M}$ to $\mathrm{mM}$ for galectins), limited chemical and metabolic stability, and high polarity leading to low bioavailability and rapid clearance. Multivalent inhibitors against galectins have almost exclusively been decorated with natural saccharides ${ }^{[28-40]}$ and thus interact with the binding site as natural saccharides but in addition may or may not make use of the affinity-enhancing glycoside clustering effect. One exception is Pieter's development of galectin-targeting photoaffinitylabelling structures, which incorporated a photo-reactive and affinity-enhancing benzophenone ether at $\mathrm{O}\left(3^{\prime}\right)$ of multivalently presented lactosides. ${ }^{[41]}$ In a recent study with a panel of mono- to divalent lactosides binding to galectin-1 and to a mutant with diminished dimerization, and thus cross-linking capability, it was discovered that divalent lactosides most likely do not cross-link different galectin-1 molecules, but rather bind a secondary lactose site. ${ }^{[42]}$

Small peptide and glycopeptide inhibitors have been prepared by solid-phase synthesis ${ }^{[43-45]}$ or via phage-display libraries. ${ }^{[46,47]}$ One of the phage-display-derived peptides displayed an impressive nanomolar affinity for galectin-3 ${ }^{[47]}$ but it remains 
to demonstrate that they interact with the galactose-binding site of the galectin-3 CRD. A peptide with anti-angiogenesis activity, Anginex, was discovered to interact with galectin-1, ${ }^{[24,25]}$ but its precise mechanism of action remains unclear. It indeed possesses potent anti-angiogenetic properties in vivo and is hence an interesting anti-tumor lead compound.

Anti-galectin antibodies have been demonstrated ${ }^{48]}$ to inhibit tumor cell aggregation and adhesion thus preventing metastasis. A dominant negative galectin construct was investigated in a human breast cancer mouse model. ${ }^{[49]}$ In this study, an $\mathrm{N}$-truncated galectin-3 construct, i.e. the galectin-3 terminus (Gal-3C) that contains the CRD, was used to compete out endogenous galectin-3 binding to endogenous ligands. Since Gal-3C cannot multimerize due to the lack of $\mathrm{N}$-terminus, it binds to natural ligands but does not confer any further function or signaling. Moreover, anti-sense oligodeoxynucleotides (ODN) and anti-sense interfering RNA (siRNA) have been reported to display anti-galectin activities in glioma and glioblastoma models. ${ }^{[50]}$ Although, comparatively little effort has been directed towards high-throughput screening of galectins against large compound libraries, a few examples have been published where non-carbohydrate synthetic inhibitors have been identified to act by allosteric inhibition of galectin-3. ${ }^{[51]}$ Finally, synthetic, small-molecule inhibitors bind in competition with endogenous ligands to prevent normal galectin function. They can be made more hydrophobic than other inhibitors, allowing improved bioavailability. Importantly, they can potentially be made higher-affinity than natural saccharide ligand fragments, thus requiring lower concentrations to compete successfully with the natural ligands.

\section{Small-molecule Inhibitor Design and Synthesis}

The availability of detailed structural information of galectin-ligand complexes has helped development of galectin inhibitors immensely. An early example is the $\mathrm{X}$-ray structure of galectin-3 in complex with $\mathrm{N}$-acetyllactosamine (LacNAc) ${ }^{[52]}$ in which a carbohydrate binding groove can be seen extending in a direction protruding beyond the 3'-position of the galactose moiety. The galectin CRDs have been divided into subsites $A-E,{ }^{[1,53,54]}$ where subsite $\mathrm{C}$ is the galactose site and the nearby subsite D accommodates another saccharide e.g. $\mathrm{N}$-acetylglucosamine in case of LacNAc (Fig. 1). Furthermore, while all galectins have the A-E subsites, individual members of the galectin family often display additional subsites along the more or

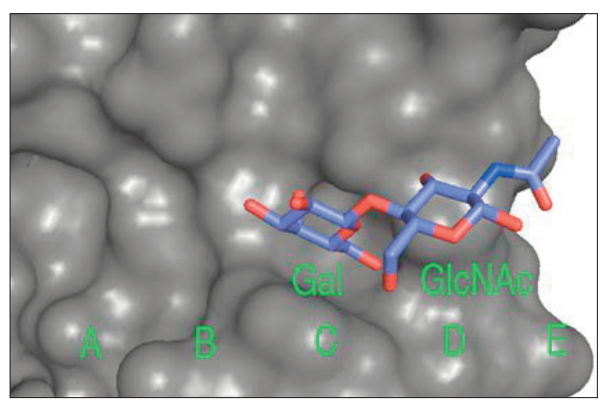

Fig. 1. X-ray structure of galectin-3 cocrystallized with LacNAc. Subsites C-D harbor galactose and $\mathrm{N}$-acetylglucosamine, respectively, while subsites $A-B$ extend beyond galactose $\mathrm{HO}(3)$. Subsite $\mathrm{E}$ extends beyond the $N$-acetyl group of LacNAc.

less conserved extended groove harboring the A-E subsites. The discussion on smallmolecule galectin inhibitors is categorized based on which subsite is targeted by their synthetic modifications.

\subsection{Inhibitors Derivatized at Galac- tose C(3) - Targeting Subsite A-B}

In an early investigation targeting subsites A and B, 3'-benzamido-LacNAc derivatives were discovered as the first small monovalent synthetic galectin-3 inhibitors with sub-micromolar affinity (Fig. 2a). ${ }^{[57]}$ The amide confers improved affinity and may also confer improved hydrolytic and enzymatic stability versus $e . g$. the corresponding esters. An X-ray crystal structure of galectin-3 co-crystallized with one 3'-benzamido-LacNAc derivative ${ }^{58]}$ revealed that the arginine ( $\operatorname{Arg} 144)$ in the extended subsites A-B moved over $3 \AA$, as compared to its conformation in complex with LacNAc, to create a cavity for the aromatic benzamido-moiety and to simultaneously sandwich it (Fig. 2b). However, a more recent structural study suggests that the galectin-3 conformation with Arg144 moved $3 \AA$ is differently populated depending on the fine structure of the benzamide. [59] Interestingly, this study also suggested, based on NMR relaxation studies, that upon ligand binding an increased conformational entropy in galectin-3 contributes significantly to the free energy of binding. [59]

The major affinity increase by the benzamido group likely originates from surface complementarity favoring dispersion forces with the protein and solvophobic effects, i.e. affinity driven largely by desolvation effects. However, a large contribution is also believed to come from the $\pi$-cation interaction ${ }^{[60]}$ with the $\operatorname{Arg} 144$ guandinium group. Following the discovery that aromatic galactose $\mathrm{C}(3)$-amides conferred large affinity enhancements for galectin-3, subsequent studies investigated other structural motifs targeting subsite A-B. Installation of 1,4-triazoles at galactose $\mathrm{C}(3)$ was readily done with a 3-azido3 -deoxy- $\beta$-D-galactoside and a suitable terminal alkyne ${ }^{[61-63]}$ (Fig. 2a). The galactose C(3)-triazoles were demonstrated to be inhibitors of galectin-3[64,65] with efficiencies approaching those of the corresponding aromatic galactose $\mathrm{C}(3)$-amides. In lieu of the galactose $\mathrm{C}(3)$-benzamides and $\mathrm{C}(3)$-triazoles, the corresponding galactose $\mathrm{C}(3)$-thiourea derivatives were proven to inhibit galectin-7 and $9 \mathrm{~N}$ with close to an order of magnitude higher affinity than the parent lacNAc glycoside (Fig. 2). ${ }^{[66]}$

Simple benzyl ethers at galactose $\mathrm{O}(3)$ have weaker affinities than the corresponding aromatic $\mathrm{C}(3)$-amides. ${ }^{[67]}$ Triazolylmethyl ethers attached to galactose $\mathrm{O}(3)$ appear however to be a promising alternative towards $\mathrm{O}(3)$-substituted derivatives targeting subsites $\mathrm{A}-\mathrm{B}$ in galectin-1, as a triazol-1-yl-methyl ether at $\mathrm{O}(3)$ of phenyl thio-galactoside gave a 40-fold enhancement over galactose in affinity for galectin-1. ${ }^{[68]}$ The observation of watermediated hydrogen bonds between the C(3)-amide functionality and galectin-3 in the X-ray structure ${ }^{[58]}$ may provide a plausible explanation for the higher affinity of $\mathrm{C}(3)$-amides over $\mathrm{O}(3)$-ethers.

\subsection{Inhibitors Targeting Subsite $E$}

Galectin carbohydrate binding sites are rich in arginine residues and the success in the case of galectin-3 at discovering aromatic galactose $\mathrm{C}(3)$-amides as sub- $\mu \mathrm{M}$ inhibitors was due to interaction with Arg144 in subsite B. Building on arene-arginine interactions as an affinityenhancing strategy, comparatively simple inhibitors targeting another arginine side chain in galectin-3 (Arg186) and the corresponding $\operatorname{Arg} 74$, Arg75, and Arg 87 in galectin-1, 7, and 9N, were synthesized by lactose $\mathrm{O}(2)$ benzoylations (Fig. 3). The lactose 2- $O$-benzoates were hypothesized to stack face-to-face to these Arg sidechains to form cation- $\pi$ interaction and indeed low $\mu \mathrm{M}$ inhibitors that were superior to lactose or lacNAc were identified. [69] The aromatic aglycon of phenyl thio-lactosides could be interacting with subsite $\mathrm{E}$, but no large affinity enhancement due to the aromatic aglycon arose. However, oxidizing the thio-lactoside to the corresponding sulfone led in one case to a significant affinity improvement for galectin-1, which was interpreted as being due to a decreased electron density on lactose $\mathrm{HO}(3)$ enhancing hydrogen bonding to a glutamate side chain. ${ }^{[70]}$ Lactulose amines ${ }^{[19,20,71]}$ and lactosyl steroids ${ }^{[23]}$ described above as having in vivo galectin-inhibiting activities presumably interact in subsite $\mathrm{E}$ with their non-carbohydrate moieties. 
a)

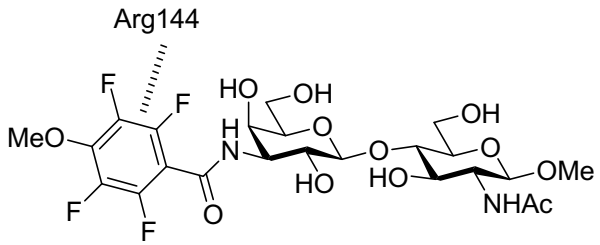

Subsite $A$

$B$

C

$D$

E

1st generation 3'-amido lacNAc derivative $\mathrm{K}_{\mathrm{d}} 880 \mathrm{nM}$ for galectin- $3^{\mathrm{a})}$

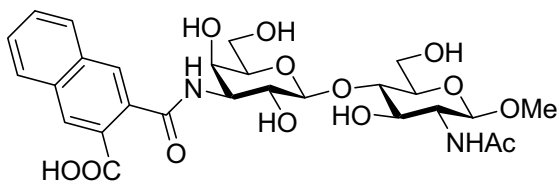

Subsite A $B$

C

$D$

2nd generation 3'-amido lacNAc derivative $\mathrm{K}_{\mathrm{d}} 320 \mathrm{nM}$ for galectin- $3^{\mathrm{a})}$

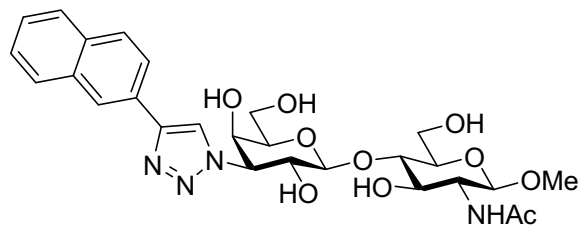

Subsite $A$

$$
B
$$

C

$D$

3'-Triazolyl lacNAc derivative $\mathrm{K}_{\mathrm{d}} 660 \mathrm{nM}$ for galectin-3 ${ }^{\mathrm{a})}$

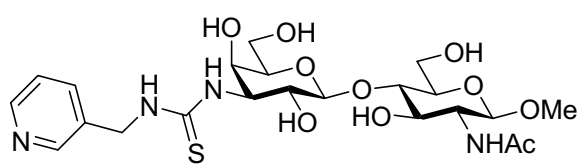

Subsite A

$$
B
$$

C

$D$

3'-Thiourea lacNAc derivative $\mathrm{K}_{\mathrm{d}} 23 \mu \mathrm{M}$ for galectin- $7^{\mathrm{a})}$

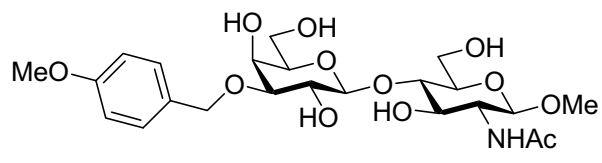

Subsite $A$

$$
\begin{array}{lcc}
B & C & D \\
3 & \text { 3-O-Benzyl lacNAc derivative }
\end{array}
$$

$\mathrm{K}_{\mathrm{d}} 13 \mu \mathrm{M}$ for galectin- $3^{\mathrm{a})}$<smiles>O=C(O)Cn1cc(COC2OC3C(O)C(O)C(Sc4ccccc4)OC3(CO)C2O)nn1</smiles>

Subsite $A$

$$
B
$$

C

$D$

3-O-Triazolylmethyl galactose derivative $\mathrm{K}_{\mathrm{d}} 1.25 \mathrm{mM}$ for galectin- ${ }^{\mathrm{b}}$ )

b)

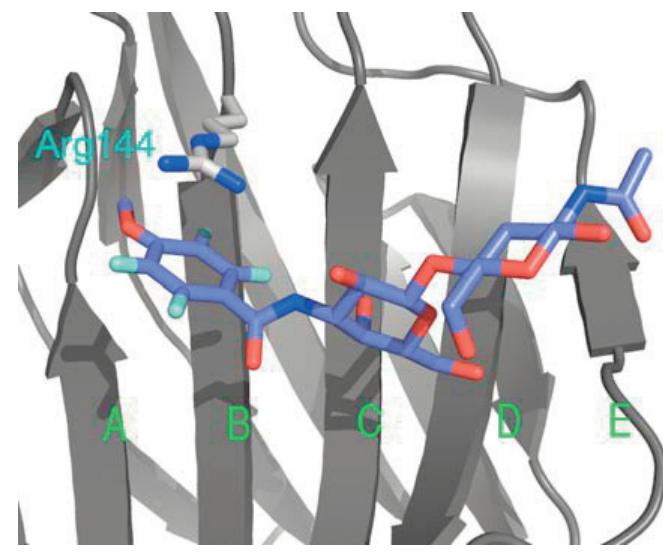

Fig. 2. a) O(3)- and $\mathrm{C}(3)$-derivatized galactosides targeting galectin subsites A-B. $K_{d}$ values are determined by a) competitive fluorescence polarization assay, ${ }^{[5,56]}$ or by b) inhibition of haemagglutination. b) X-ray structure of galectin-3 cocrystallized with a 3'-benzamido-LacNAc derivative.

Lactosyl sulfone

$\mathrm{K}_{\mathrm{d}} 40 \mu \mathrm{M}$ for galectin- ${ }^{\mathrm{b}}$ )

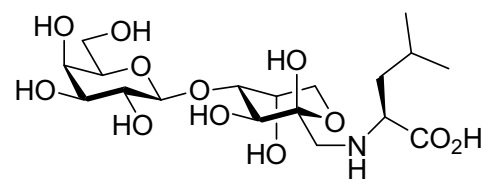

Subsite C

$D$

\section{E}

Lactulosyl-leucine

Augments sensitivity to taxol in MDA-MB-435 a in vivo model

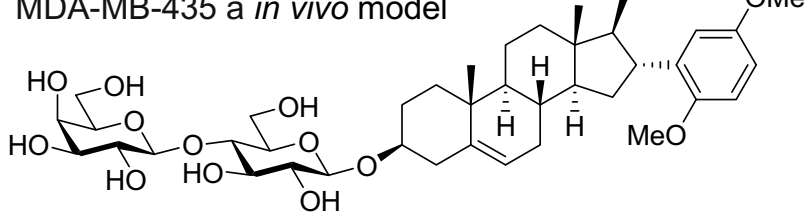

Subsite C

$$
\begin{array}{ll}
D & E \\
\text { Lactosyl steroid }
\end{array}
$$

Augments sensitivity to cisplatin in P388 lymphoma and U373 glioblastoma in vivo models

Fig. 3. Aromatic lactose $\mathrm{O}(2)$-esters, aryl lactosides, lactulose amines, and a lactosylsteroid targeting galectin subsite $E . K_{d}$ values are determined by a) competitive fluorescence polarization assay ${ }^{[55,56]}$ or by b) inhibition of haemagglutination. 


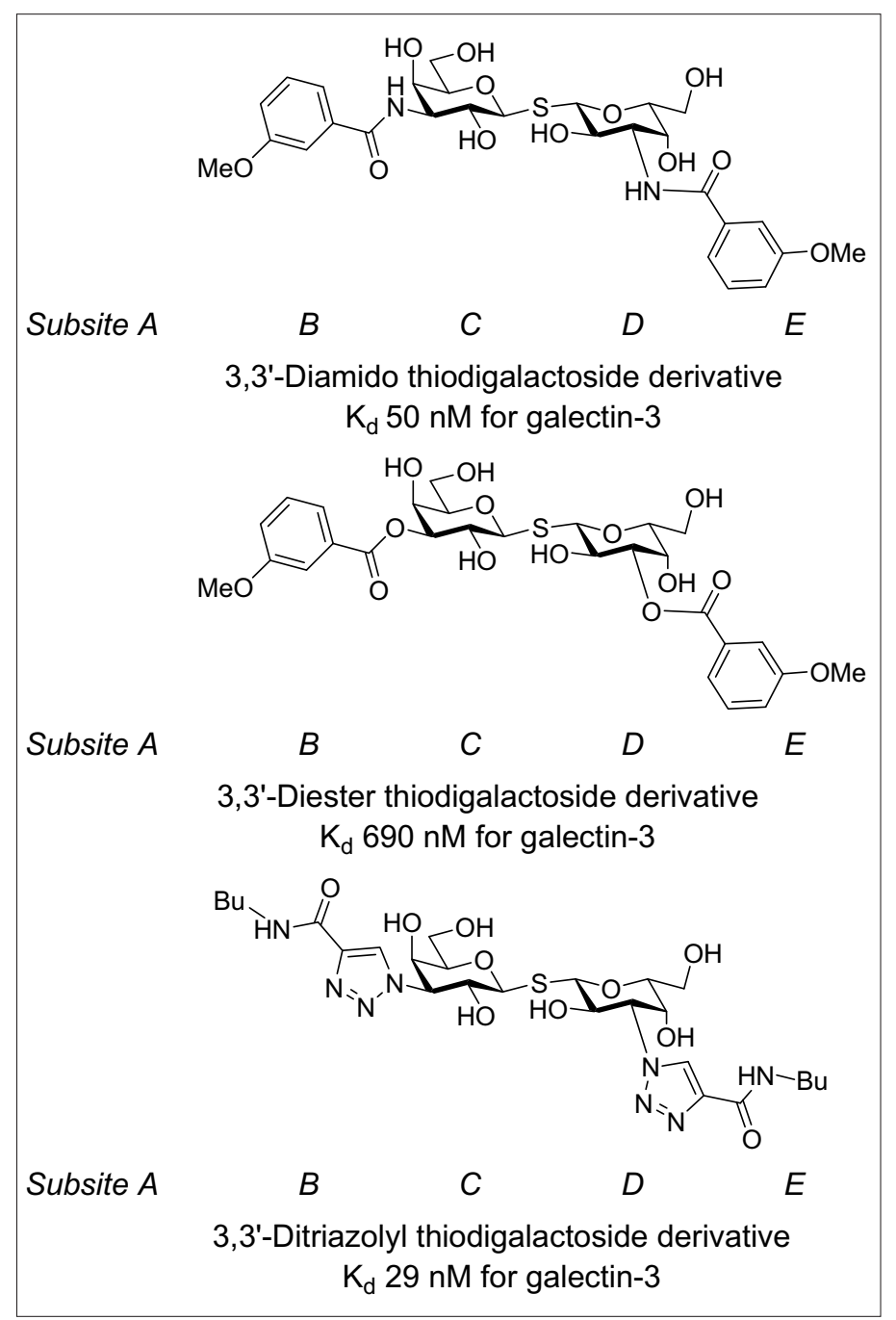

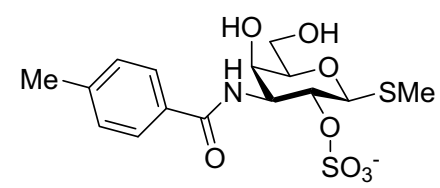

Subsite A

B

C

D

2-Sulfo-3-benzamido galactoside derivative $\mathrm{K}_{\mathrm{d}} 87 \mu \mathrm{M}$ for galectin- $3^{\mathrm{a})}$

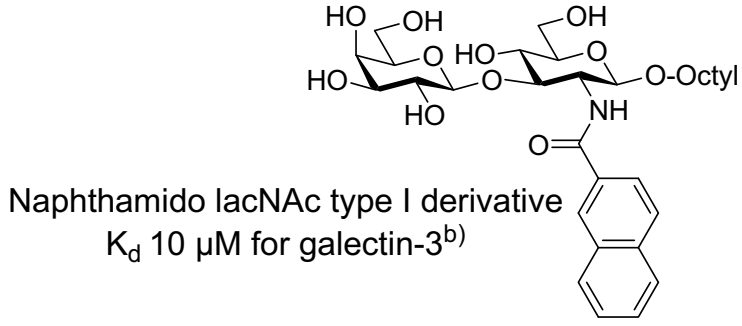

Subsite A

B

C

$D$
Fig. 4.

Thiodigalactoside

3,3'-diamides,

-diesters, and

-di-triazoles. The

high affinities of

thiodigalactoside

derivatives for

galectin-3 are

hypothesized to result

from double arginine-

ligand interactions. $\mathrm{K}_{\mathrm{d}}$

values are determined

by a competitive

fluorescence

polarization

assay. ${ }^{[55,56]}$

Fig. 5. Inhibitors

that target grooves perpendicular to the A-E subsites. $K_{d}$ values are determined by a) competitive fluorescence polarization assay, ${ }^{[55,56]}$ or b) frontal affinity chromatography. ${ }^{[78]}$ do-thiodigalactosides for galectin-3 was later reflected by one 3,3'-di-benzamidothiodigalactoside's efficient inhibitory effect on galectin-3-regulated macrophage alternative M2 differentiation, and hence fibrosis, in vitro and ex vivo. ${ }^{[74]}$

Compared to the parent LacNAc derivatives (section 3.1 above) the correspond- ing 3,3'-di-triazolyl-thiodigalactosides revealed comparable low-nM affinities for galectin-3, but on the other hand had different selectivity profiles towards the galectins. ${ }^{[65]}$ The high affinity of 3,3'-ditriazolyl-thiodigalactosides for galectin-3 was successfully exploited in the development of a galectin-3 photoaffinity probe giving low non-specific background labeling of proteins. ${ }^{[75]}$

Synthetically simpler aromatic thiodigalactoside 3,3'-di-esters were found to show activity on tumor cell motility (and hence chemotherapeutica sensitivity) ${ }^{[76]}$ and on ex vivo human thyroid cancer cell sensitivity to pro-apoptotic chemotherapeutica. ${ }^{[77]}$

\subsection{Saccharide Modifications Tar- geting Subsites Perpendicular to the Natural Ligand Binding Groove}

While the $\alpha$-face of galactose resides on the plane of a Trp side-chain, the $\beta$-face of galactose is 'zipped' up by forming hydrogen bonds with the galectin CRD. As all galectins exploit one to three basic amino acids (Arg or His) to form such polar interaction with galactose, it appeared reasonable to assume that electron-rich substituents added to galactose may engage in strong interactions with His or Arg side chains. The $\mathrm{HO}(4)$ and $\mathrm{HO}(6)$ of galactose are engaged in key polar interactions with all galectins, while galactose $\mathrm{HO}(2)$ is not. Based on this notion, a 3-benzamido-3deoxy- $\beta$-D-galactoside was derivatized at $\mathrm{O}(2)$ with electron-rich substituents (Fig. 5 ) and it was proved that this resulted in enhanced binding to galectin-3. The most promising $\mathrm{O}(2)$ substituent was a sulfate and molecular modeling suggested that the sulfate indeed interacts with Arg144 of this galectin. [79]

One LacNAc derivative carrying a 2-naphthamido group showed enhanced affinity by close to one order of magnitude for galectin-3. ${ }^{[78]}$ Given that the $\mathrm{HO}(4)$ of this type I disaccharide (Gal 1 1-3GlcNAc) takes the place of $\mathrm{OH}(3)$ in a type II disaccharide (Gal $\beta 1-4 \mathrm{GlcNAc})$ and is involved in hydrogen bonding with Glu184 and Arg 162 (i.e. forming a hydrogen bond triad, see Fig. 1B in ref. [69] and Fig. 1b and $c$ in ref. [80]), as seen in structures of galectins in complex with natural saccharides occupying subsite $\mathrm{D}$, the naphthamido group is bound to be positioned in the proximity to Trp181 lining one side of subsite $\mathrm{C}-\mathrm{D}$. Thus the 2-naphthamido moiety may be involved in a T-stacking arenearene interaction with Trp181, which is an interaction mode worth pursuing further for inhibitor discovery.

\subsection{Inhibitors Mimicking Glc or GIcNAc of Natural Ligands - Targeting Subsite $D$}

Galactosyl oximes, where anomeric aromatic oximes mimic Glc/GlcNAc, were demonstrated to provide efficient monosaccharide inhibitors of galectin-3. ${ }^{[81]}$ Properly trisubstituted phenyl aglycons of 1-thio- $\beta$-D-galactosides were found to mimic Glc binding properties of galectin-7 and were comparatively efficient inhibitors 
(Fig. 6). ${ }^{[82]}$ The galatosyl oximes have been combined with galactose C(3)-triazolyl substituents (see section 3.1 and Fig. 2a) to further improve affinity and thus providing promise for drug development. ${ }^{[83]}$ Collections of $O$ - and $C$ - $\beta$-D-galactosides with aglycons incorporating isoxazole- or triazole moieties that would interact with subsite D were found by Roy et al. to inhibit galectin-1 with promising $\mu \mathrm{M}$ affinities and with significant selectivity over galectin-3[68] (Fig. 6). [84]

\subsection{Inhibitors Mimicking Galactose - Targeting Subsite C}

Finally, other pyranosides having at least one 1,2-cis-diol may be explored as galactose mimics. Within this context, we developed triazolyl $\beta$-D-mannopyranosides as galectin inhibitors in which the anomeric triazolyl moiety mimicked a galactose $\mathrm{C}(3)$-triazole moiety and mannose $\mathrm{O}(2)$ mimicked galactose $\mathrm{O}(4)$ (Fig. 7). ${ }^{\left[{ }^{[5]}\right.}$ Furthermore, the $\beta$-face of galectinbound galactosides is directed towards a line of Arg and/or His side chains, which laid the basis for designing and synthesizing $\beta$-D-talopyranosides as galectin inhibitors. The inverted configuration at talose $\mathrm{C}(2)$, as compared to galactose $\mathrm{C}(2)$, was hypothesized to direct $\mathrm{O}(2)$, as well as $\mathrm{O}(2)$ substituents towards the line of Arg and/or His side chains. Indeed, taloside derivatives were found to inhibit galectin-3, 4C, and $8 \mathrm{~N}$ and the two later galectins in fact preferred the talose over the galactose configuration. ${ }^{[86]}$ Hence, talopyranose is a more promising scaffold than galactopyranose for the development of inhibitors targeting galectin-4 and 8 .

\section{Outlook}

It is commonly stated as a general truth that monovalent carbohydrate-protein interactions are weak and that lectins therefore make poor drug targets. However, galectins typically bind natural oligosaccharide ligands with low $\mu \mathrm{M}$ affinity, or in some cases even nM affinity as for galectin-8N binding sialyllactose. ${ }^{[14]}$ Indeed, several studies have through combination of monosaccharide mimicking and appending non-carbohydrate structures to saccharide scaffold proved that it is possible to develop small-molecule galectin inhibitors with low nM affinities required for drug leads. Challenges that remain to be tackled are improving ADME properties of the compounds, in particular bioavailability, stability to in vivo degradation, and clearance. It can be expected that further structural modification of galectin inhibitors can address these challenges and that they eventually

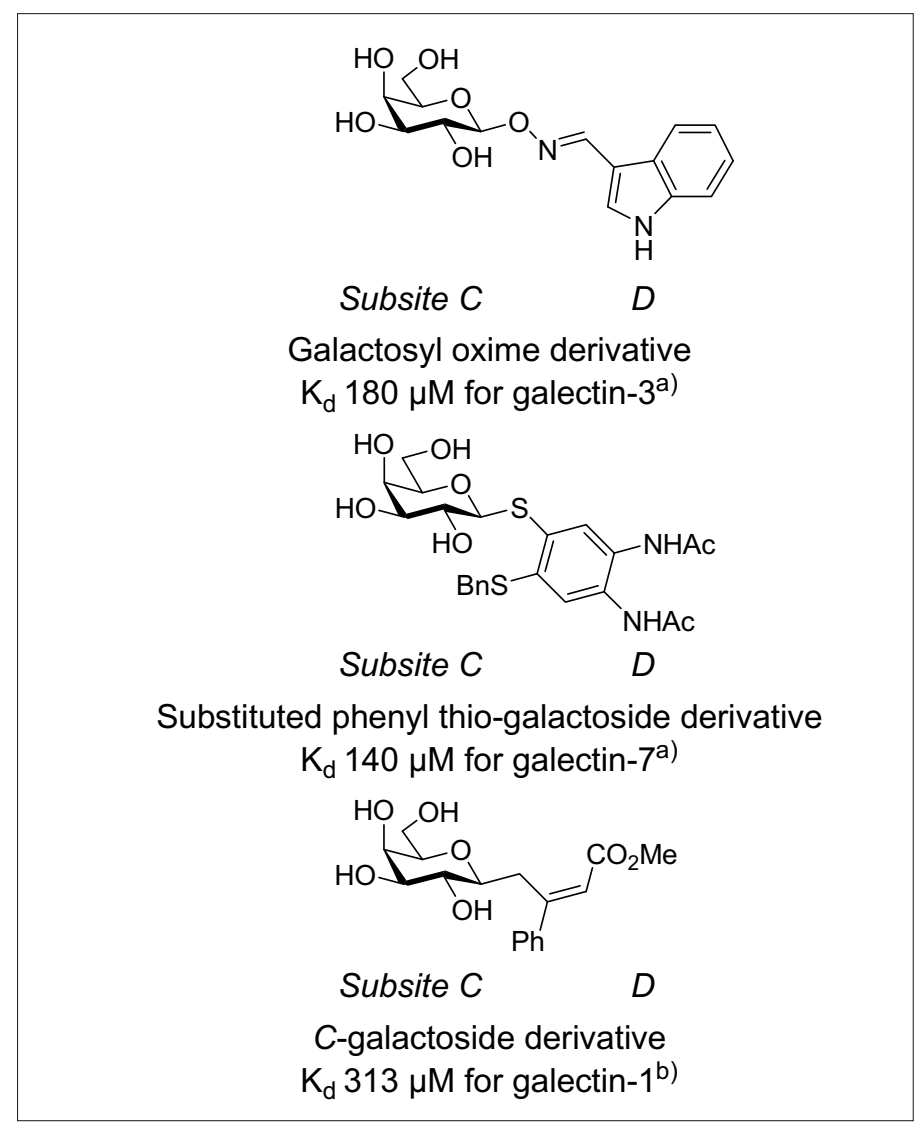

Fig. 6. Galactosides investigated as subsite D-targeting galectin inhibitors. $\mathrm{K}_{\mathrm{d}}$ values are determined by a) competitive fluorescence polarization assay ${ }^{[5,56}$ or by b) inhibition of haemagglutination.

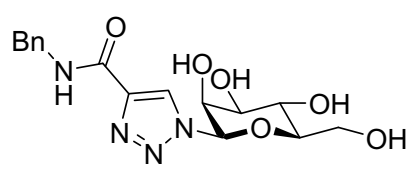

Subsite $A$

$B$ C

3'-Triazolyl mannoside derivative $\mathrm{K}_{\mathrm{d}} 540 \mu \mathrm{M}$ for galectin-9 N-terminal domain

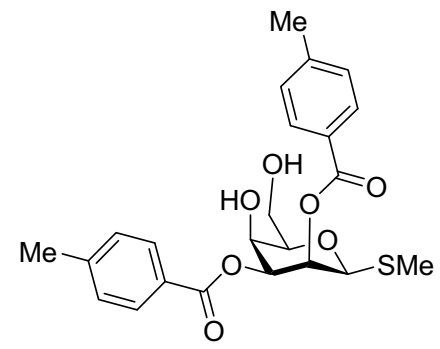

Subsite $A \quad B \quad C$

2,3-Di-benzoyl taloside derivative $\mathrm{K}_{\mathrm{d}} 160 \mu \mathrm{M}$ for galectin-4 C-terminal domain
Fig. 7. Mannosides and talosides mimicking galactose-binding in subsite $C$. $K_{d}$ values are determined by competitive fluorescence polarization assay. ${ }^{[5,56]}$ will be developed into galectin-targeting drugs that oppose tumor progression and inflammatory conditions via novel mechanisms.

\section{Acknowledgements}

This work was supported by the Swedish Research Council and the Royal Fysiographic Society, Lund.

Received: October 25, 2010

[1] H. Leffler, S. Carlsson, M. Hedlund, Y. Qian, F. Poirier, Glycoconj. J. 2004, 19, 433.
[2] D. Delacour, C. Greb, A. Koch, E. Salomonsson, H. Leffler, A. Le Bivic, R. Jacob, Traffic 2007, 8, 379.

[3] M. A. Toscano, G. A. Bianco, J. M. Ilarregui, D. O. Croci, J. Correale, J. D. Hernandez, N. W. Zwirner, F. Poirier, E. M. Riley, L. G. Baum, G. A. Rabinovich, Nat. Immunol. 2007, 8, 825 .

[4] M. Demetriou, M. Granovsky, S. Quaggin, J. W. Dennis, Nature 2001, 409, 733.

[5] E. A. Partridge, C. Le Roy, G. M. Di Guglielmo, J. Pawling, P. Cheung, M. Granovsky, I. R. Nabi, J. L. Wrana, J. W. Dennis, Science 2004, 306, 120.

[6] K. S. Lau, E. A. Partridge, A. Grigorian, C. I. Silvescu, V. N. Reinhold, M. Demetriou, J. W. Dennis, Cell 2007, 129, 123. 
[7] N. L. Perillo, K. E. Pace, J. J. Seilhamer, L. G. Baum, Nature 1995, 378, 736.

[8] M. T. Elola, C. Wolfenstein-Todel, M. F. Troncoso, G. R. Vasta, G. A. Rabinovich, Cell. Mol. Life Sci. 2007, 64, 1679.

[9] F.-T. Liu, G. A. Rabinovich, Nat. Rev. Cancer 2005, 5, 29

[10] R. Y. Yang, G. A. Rabinovich, F. T. Liu, Expert. Rev. Mol. Med. 2008, 10, e17.

[11] G. A. Rabinovich, M. A. Toscano, Nat. Rev. Immunol. 2009, 9, 338.

[12] G. R. Vasta, Nat. Rev. Microbiol. 2009, 7, 424.

[13] F. T. Liu, G. A. Rabinovich, Ann. NY Acad. Sci. 2010, 1183,158

[14] S. Carlsson, C. T. Öberg, M. C. Carlsson, A. Sundin, U. J. Nilsson, D. Smith, R. D. Cummings, J. Almkvist, A. Karlsson, H. Leffler, Glycobiology 2007, 17, 663 .

[15] S. Carlsson, M. C. Carlsson, H. Leffler, Glycobiology 2007, 17, 906.

[16] D. Delacour, A. Koch, R. Jacob, Traffic 2009, 10, 1405 .

[17] D. Schneider, C. Greb, A. Koch, T. Straube, A. Elli, D. Delacour, R. Jacob, Eur. J. Cell Biol. 2010, 89,788

[18] N. Demotte, V. Stroobant, P. J. Courtoy, P. Van Der Smissen, D. Colau, I. F. Luescher, C. Hivroz, J. Nicaise, J.-L. Squifflet, M. Mourad, D. Godelaine, T. Boon, P. van der Bruggen, Immunity 2008, 28, 414.

[19] G. V. Glinsky, J. E. Price, V. V. Glinsky, V. V. Mossine, G. Kiriakova, J. B. Metcalf, Cancer Res. 1996, 56, 5319.

[20] V. V. Glinsky, G. Kiriakova, O. V. Glinskii, V. V. Mossine, T. P. Mawhinney, J. R. Turk, A B. Glinskii, V. H. Huxley, J. E. Price, G. V Glinsky, Neoplasia 2009, 11, 901.

[21] P. Nangia-Makker, V. Hogan, Y. Honjo, S. Baccarini, L. Tait, R. Bresalier, A. Raz, J. Natl. Cancer Inst. 2002, 94, 1854.

[22] K. J. Pienta, H. Naik, A. Akhtar, K. Yamazaki, T. S. Reploge, J. Lehr, T. L. Donat, L. Tait, V. Hogan, A. Raz, J. Natl. Cancer Inst. 1995, 87 , 348.

[23] L. Ingrassia, P. Nshimyumukiza, J. Dewelle, F. Lefranc, L. Wlodarczak, S. Thomas, G. Dielie, C. Chiron, C. Zedde, P. Tisnes, R. van Soest, J. J. Braekman, F. Darro, R. Kiss, J. Med. Chem. 2006, 49, 1800.

[24] R. Dings, D. van der Schaft, B. Hargittai, J Haseman, A. W. Griffioen, K. H. Mayo, Cancer Lett. 2003, 194, 55.

[25] V. L. J. L. Thijssen, R. Postel, R. J. M. G. E Brandwijk, R. P. M. Dings, I. Nesmelova, S. Satijn, N. Verhofstad, Y. Nakabeppu, L. G. Baum, J. Bakkers, K. H. Mayo, F. Poirier, A W. Griffioen, Proc. Natl. Acad. Sci. 2006, 103 15975.

[26] R. J. Pieters, ChemBioChem 2006, 7, 721.

[27] L. Ingrassia, I. Camby, F. Lefranc, V. Mathieu, P. Nshimyumukiza, F. Darro, R. Kiss, Curr. Med. Chem. 2006, 13, 3513.

[28] S. André, H. Kaltner, T. Furuike, S.-I. Nishimura, H.-J. Gabius, Bioconj. Chem. 2004, $15,87$.

[29] S. André, B. Liu, H.-J. Gabius, R. Roy, Org. Biomol. Chem. 2003, 1, 3909.

[30] S. André, P. J. C. Ortega, M. A. Perez, R. Roy, H.-J. Gabius, Glycobiology 1999, 11, 1253.

[31] S. André, R. J. Pieters, I. Vrasidas, H. Kaltner, I. Kuwabara, F.-T. Liu, R. M. J. Liskamp, H.-J. Gabius, ChemBioChem 2001, 2, 822

[32] S. André, F. Sansone, H. Kaltner, A. Casnati, J. Kopitz, H.-J. Gabius, R. Ungaro, ChemBioChem 2008, 9, 1649.

[33] S. André, D. Specker, N. V. Bovin, M. Lensch, H. Kaltner, H.-J. Gabius, V. Wittmann, Bioconj. Chem. 2009, 20, 1716.

[34] J. M. Belitsky, A. Nelson, J. Hernandez, L. G. Baum, J. F. Stoddart, Chem. Biol. 2007, 14 1140.
[35] S. G. Gouin, J. M. García Fernández, E. Vanquelef, F.-Y. Dupradeau, E. Salomonsson, H. Leffler, M. Ortega-Muñoz, U. J. Nilsson, J. Kovensky, ChemBioChem 2010, 11, 1430.

[36] R. Leyden, T. Velasco-Torrijos, S. André, S. Gouin, H.-J. Gabius, P. V. Murphy, J. Org. Chem. 2009, 74, 9010.

[37] A. Nelson, J. M. Belitsky, S. Vidal, C. S. Joiner, L. G. Baum, J. F. Stoddart, J. Am. Chem. Soc. 2004, 126, 11914

[38] N. L. Pohl, L. L. Liessling, Synthesis 1999, 1515.

[39] J. Tejler, J. Tullberg, T. Frejd, H. Leffler, U. J. Nilsson, Carbohydr. Res. 2006, 34, 1353.

[40] I. Vrasidas, S. André, P. Valentini, C. Böck, M. Lensch, H. Kaltner, R. M. J. Liskamp, H.-J. Gabius, R. J. Pieters, Org. Biomol. Chem. 2003, 1,803 .

[41] L. Ballell, M. Van Scherpenzeel, K. Buchalova, R. M. J. Liskamp, R. J. Pieters, Org. Biomol. Chem. 2006, 4, 4387.

[42] E. Salomonsson, A. Larumbe, J. Tejler, E. Tullberg, H. Rydberg, A. Sundin, T. Khabut, T. Frejd, Y. D. Lobsanov, J. M. Rini, U. J. Nilsson, H. Leffler, Biochemistry 2010, 49, 9518.

[43] S. André, C. Maljaars, K. Halkes, H.-J. Gabius, J. Kamerling, Bioorg. Med. Chem. Lett. 2007, $17,793$.

[44] C. J. Arnush, S. André, P. Valentini, M. Lensch, R. Russwurm, H.-C. Siebert, M. J. E. Fischer, H.-J. Gabius, R. J. Pieters, Bioorg, Med. Chem. 2004, 14, 1437.

[45] C. E. P. Maljaars, S. André, K. M. Halkes, H.-J. Gabius, J. P. Kamerling, Anal. Biochem. 2008, $378,190$.

[46] S. André, C. Arnusch, I. Kuwabara, R. Russwurm, H. Kaltner, H.-J. Gabius, R. Pieters, Bioorg. Med. Chem. 2005, 13, 563.

[47] J. Zou, V. V. Glinsky, L. A. Landon, L. Matthews, S. L. Deutscher, Carcinogenesis 2005, 26, 309.

[48] L. Meromsky, R. Lotan, A. Raz, Cancer Res. 1986, 46, 5270 .

[49] C. M. John, H. Leffler, B. Kahl-Knutsson, I. Svensson, G. A. Jarvis, Clin. Cancer Res. 2003, 9, 2374.

[50] I. Camby, M. Le Mercier, F. Lefranc, Kiss, R. Glycobiology 2006, 16, 137R.

[51] A. W. Kahsai, J. Cui, H. U. Kaniskan, P. P. Garner, G. Fenteany, J. Biol. Chem. 2008, 283, 24534.

[52] J. Seetharaman, A. Kanigsberg, R. Slaaby, H. Leffler, S. H. Barondes, J. M. Rini, J. Biol. Chem. 1998, 273, 13047.

[53] J. Hirabayashi, T. Hashidate, Y. Arata, N. Nishi, T. Nakamura, M. Hirashima, T. Urashima, T. Oka, M. Futai, W. E. G. Muller, F. Yagi, K.-I. Kasai, Biochem. Biophys. Acta 2002, 1572, 232.

[54] R. Knibbs, N. Agrwal, J. L. Wang, I. J. Goldstein, J. Biol. Chem. 1993, 268, 14940.

[55] P. Sörme, B. Kahl-Knutsson, M. Huflejt, U. J. Nilsson, H. Leffler, Anal. Biochem. 2004, 334, 36.

[56] P. Sörme, B. Kahl-Knutsson, U. Wellmar, U. J. Nilsson, H. Leffler, Meth. Enzymol. 2003, 362, 504.

[57] P. Sörme, Y. Qian, P.-G. Nyholm, H. Leffler, U. J. Nilsson, ChemBioChem 2002, 3, 183.

[58] P. Sörme, P. Arnoux, B. Kahl-Knutsson, H. Leffler, J. M. Rini, U. J. Nilsson, J. Am. Chem. Soc. 2005, 127, 1737.

[59] C. Diehl, O. Engström, T. Delaine, M. Håkansson, S. Genheden, K. Modig, H. Leffler, U. Ryde, U. J. Nilsson, M. Akke, J. Am. Chem. Soc. 2010, 132, 14577.

[60] J. C. Ma, D. A. Dougherty, Chem. Rev. 1997, 97, 1303.

[61] C. M. Tornøe, M. Meldal, in 'Peptides: The Wave of the Future, Proceeding of the Second International and the Seventeenth American Peptide Symposium', Ed. M. Lebl, R. A.
Houghten, Springer: San Diego, CA, United States, 2001, p. 263

[62] C. M. Tornøe, C. Christensen, M. Meldal, J. Org. Chem. 2002, 67, 3057.

[63] V. V. Rostovtsev, L. G. Green, V. V. Fokin, K B. Sharpless, Angew. Chem. Int. Ed. 2002, 41, 2596.

[64] B. A. Salameh, H. Leffler, U. J. Nilsson, Bioorg. Med. Chem. Lett. 2005, 15, 3344

[66] B. A. Salameh, A. Sundin, H. Leffler, U. J. Nilsson, Bioorg. Med. Chem. 2006, 14, 1215.

[67] P. Sörme, B. Kahl-Knutsson, U. Wellmar, B. G. Magnusson, H. Leffler, U. J. Nilsson, Meth. Enz. 2003, 363, 157.

[68] D. Giguere, R. Patnam, M.-A. Bellefleur, C. St.Pierre, S. Sato, R. Roy, Chem. Commun. 2006, 2379.

[69] I. Cumpstey, E. Salomonsson, A. Sundin, H. Leffler, U. J. Nilsson, ChemBioChem 2007, 8, 1389.

[70] D. Giguere, S. Sato, C. Stpierre, S. Sirois, R Roy, Bioorg. Med. Chem. Lett. 2006, 16, 1668.

[71] G. A. Rabinovich, A. Cumashi, G. A. Bianco, D. Ciavardelli, I. Iurisci, M. D'Egidio, E. Piccolo, N. Tinari, N. Nifantiev, S. Iacobelli, Glycobiology 2006, 16, 210.

[72] I. Cumpstey, A. Sundin, H. Leffler, U. J. Nilsson, Angew. Chem. Int. Ed. 2005, 44, 5110.

[73] I. Cumpstey, E. Salomonsson, A. Sundin, H Leffler, U. J. Nilsson, Chem. Eur. J. 2008, 14, 4233.

[74] A. C. MacKinnon, S. L. Farnworth, P. S Hodkinson, N. C. Henderson, K. M. Atkinson, H. Leffler, U. J. Nilsson, C. Haslett, S. J. Forbes, T. Sethi, J. Immunol. 2008, 180, 2650.

[75] M. Van Scherpenzeel, E. E. Moret, L. Ballell, R. M. J. Liskamp, U. J. Nilsson, H. Leffler, R. J. Pieters, ChemBioChem 2009, 10, 1724.

[76] T. Delaine, I. Cumpstey, L. Ingrassia, M. Le Mercier, P. Okechukwu, H. Leffler, R. Kiss, U. J. Nilsson, J. Med. Chem. 2008, 51, 8109.

[77] C.-I. Lin, E. E. Whang, D. B. Donner, X. Jiang, B. D. Price, A. M. Carothers, T. Delaine, H. Leffler, U. J. Nilsson, V. Nose, F. D. Moore, D. T. Ruan, Mol. Cancer Res. 2009, 7, 1655.

[78] S. Fort, H. S. Kim, O. Hindsgaul, J. Org. Chem. 2006, 71, 7146.

[79] C. T. Öberg, H. Leffler, U. J. Nilsson, J. Med. Chem. 2008, 51, 2297.

[80] E. Salomonsson, M. C. Carlsson, V. Osla, R. Hendus-Altenburger, B. Kahl Knutson, C. T. Oberg, A. Sundin, R. Nilsson, E. NordbergKarlsson, U. J. Nilsson, A. Karlsson, J. M. Rini, H. Leffler, J. Biol. Chem. 2010, 285, 35079.

[81] J. Tejler, H. Leffler, U. J. Nilsson, Bioorg. Med. Chem. Lett. 2005, 15, 2343.

[82] I. Cumpstey, S. Carlsson, H. Leffler, U. J. Nilsson, Org. Biomol. Chem. 2005, 3, 1922.

[83] J. Tejler, B. Salameh, H. Leffler, U. J. Nilsson, Org. Biomol. Chem. 2009, 7, 3982.

[84] D. Giguere, M. Bonin, P. Cloutier, R. Patnam, C. Stpierre, S. Sato, R. Roy, Bioorg. Med. Chem. 2008, 16, 7811.

[85] J. Tejler, F. Skogman, H. J. Leffler, U. J. Nilsson, Carbohydr. Res. 2007, 342, 1869.

[86] C. T. Öberg, H. Blanchard, H. Leffler, U. J. Nilsson, Bioorg. Med. Chem. Lett. 2008, 18, 3691 . 